\title{
The Ashworth Inquiry: the lessons for psychiatry
}

\author{
Antony Maden
}

Let us begin with the obvious. Events at the Personality Disorder Unit (PDU) at Ashworth were scandalous. The Inquiry report (Fallon et al. 1999) draws attention to a fundamental breakdown in security, and is rightly critical of the staggering fact that a child was allowed to visit men convicted of the most horrendous sexual offences. The circulation of pornography, drink and drugs and the operation of businesses by men supposedly receiving treatment for their psychopathic disorders, are only marginally less shocking. All reasonable people can unite in condemnation of this mess, just as we are all against sin. The Inquiry team did a good job of establishing the truth of the allegations made by a patient who had absconded, which seemed incredible when they were first revealed.

Reasonable people can also agree that, given the extent of the failings described, some of those responsible for running the PDU would have to go. There is room for argument about how far responsibility should extend, but the Inquiry team were skilled in teasing out the failings within management, particularly over the suppression of previous, internal reports which should have set alarm bells ringing. Had the Inquiry stopped at this point, after making the appropriate recommendations, it would have fulfilled its terms of reference. It is likely that the report would have been welcomed without reservation. Much money would have been saved, and much bad feeling avoided.

Instead, the Inquiry team adopted its own wide-ranging agenda, taking in the reform of high security psychiatric services, and a comprehensive review of personality disorder and its treatment. It is not an appropriate body to consider such questions, so it is not really surprising that the result was unsatisfactory. The headline recommendation, that the hospital should be closed, appears half-baked. There is no attempt to work through the obstacles to closure, including the question of what should be done with the existing patients, and those on the waiting list. It was easy for the Secretary of State to dismiss such a radical step, presented without any detailed support.

A related problem, once the Inquiry chose to adopt a wider role than that envisaged by the terms of reference, is that of apparent bias. By sheer coincidence, publication of the Fallon report coincided with the Law Lords' overturning of their judgement in the Pinochet case, and it is interesting to compare these examples of the law at work. The Pinochet case leaves a warm glow. A former dictator accused of the most monstrous crimes was judged in a scrupulously fair manner, where even the possible appearance of bias was unacceptable. By contrast, the Ashworth report leaves a queasy feeling. The psychiatrist on the Inquiry team is a well known opponent of special hospitals and has called publicly for their closure (Bluglass, 1992). The conclusion that Ashworth should be closed inevitably brings to mind Mandy Rice-Davies' "he would say that, wouldn't he?". On the principle that Ashworth staff are entitled to the appearance of absolute fairness, it may have been better if the team had included a medical member with less committed views, if the Inquiry was going to stray into this territory.

These and other problems with the Ashworth report must be understood in the context of other psychiatric inquiries. The homicide inquiries are set up under different legislation, but the basic structure is similar. A team comprising legal chairman, medical and lay members is instructed to adopt an inquisitorial approach and to judge the performance of professionals, following an apparent or suspected failure.

Resources are often unlimited, and the team has the advantage of hindsight. At a reputed cost of $\$ 7.5 \mathrm{~m}$, the Fallon report can be seen as the grandest product of the Inquiry industry. It shares many of the faults of the homicide inquiries, on a grander scale.

The appearance of bias has already been mentioned, and examples are to be found throughout the report. The Inquiry's resources allowed it to commission various reports from experts in the field, including Dr Adrian Grounds' assessment of the present state of the PDU. His team's thorough and broadly favourable report is rejected, with little attempt at justification, in one of the most blatant examples of a blinkered approach. This problem raises difficult issues for psychiatry. To what extent should a doctor on an inquiry panel represent his or her own views. 
as opposed to the wider standards of the profession? It is a matter of concern that the Royal College of Psychiatrists offers no guidance to members who are selected to serve on such panels.

A second, general issue is the tendency of inquiries to stray beyond their terms of reference. It is increasingly common for homicide inquiries also to adopt loftier ambitions. Some have claimed to be "a model case study and teaching aid", or "a model for the way in which inquiries should be conducted". while it is becoming common to review the Mental Health Act and suggest radical reform. All are noble aims but should be undertaken in the proper place. Health service staff cooperate with inquiries on the understanding that there will be a fair attempt to address the terms of reference, and it is unreasonable that the process should be hijacked to further the ambitions or preoccupations of panel members, however laudable these may be in their own right.

A third issue for inquiries in general is the treatment of individuals by an inquisitorial process. The Fallon report's treatment of professionals has already been attacked as "a witch hunt" (Gunn, 1999). Much of the report's criticism of professionals does not pass the test of being seen to be fair. I was most concerned by the unrealistic view of medical management, where it is assumed that colleagues who do not come up to scratch can simply be removed, irrespective of the damage caused to the service, or the lack of replacements. Any manager who does not act to remove them is held accountable for all their actions. Again, this raises difficult questions for the profession. Should retired doctors sit on inquiry panels? Once a doctor leaves the fray, it is easy to lose sight of the compromises that are made in daily practice, between the ideal and the real. These compromises have always been obvious in the prison system and the special hospitals, but only an ostrich could pretend that they do not apply to other areas of psychiatry also. Inquiries are becoming the ultimate arbiters of medical standards within psychiatry, and this task is too important to be left to retired clinicians. To paraphrase one of the standards chosen by the Inquiry (p. 323, Fallon et al, 1999), general surgery would never accept a situation in which standards were set by clinicians who were no longer operating.

This rigidity and lack of awareness of mitigating circumstances is one of the most alarming aspects of the report. The message of Fallon is that any medical manager who values his or her reputation should steer clear of poorly performing hospitals. This view makes sense, only if you believe that the hospital should be closed, and will be closed. Otherwise there must be an obligation to work to raise standards, for the sake of the patients who are treated there. In this way, the Inquiry's conviction that the hospital should close leads it to adopt odd standards by which to judge professionals, who saw themselves as working to improve a flawed institution that was likely to continue to treat patients for the foreseeable future. Events have shown the latter view to be correct.

Anyone who defends doctors from criticism runs the risk of being accused of complacency, and of closing ranks. In the case of Fallon, the opposite can be argued. The odd and arbitrary standards by which some professionals are judged tend to weaken the criticisms of those who were truly at fault. The report suggests that there was gross incompetence and most readers will conclude that at least one consultant should have been sacked. The impact of this justified criticism is lessened, by dragging in those whose failings, if any, were more nebulous.

The charge of complacency can also be levelled at the report. One of its themes is that large special hospitals are bad, whereas smaller secure units are good. There is no reference to the current round of mergers that are creating mega-trusts around the country, nor is there recognition that there can be good large institutions, and bad small ones. It is left to Grounds in the report (p. 318. Fallon et ah. 1999) to point out that the patients treated in the PDU would present enormous problems wherever they were treated, whether in a large or small institution and whether in prison or in hospital. We should not forget that there have been security lapses in top security prisons, and history should have taught us that no psychiatric unit is immune to scandal. It is surely only a matter of time before one occurs in a secure unit and, in this context, it is simplistic to suggest the problem of managing the seriously personality disordered is a matter of choosing one setting over another.

The report makes some sensible points about personality disorder and its management, and includes the views of most experts in the field. Bias is also apparent here, with a preference for the views of those who are not involved in treating severe personality disorders. This is an unusual standard by which to make a choice between the conflicting views of experts but the fundamental problem is that this was the wrong setting for the debate. The team often appears natve and appears to believe that the 'treatable' and the 'untreatable' are as distinct as sheep and goats. There is little sense of the overlap between mental illness and personality disorder, or the complexity of the real world.

A final criticism of the report must be the grandiose parallel which is drawn in the Executive Summary, between the events at Ashworth and the Bristol case, involving 
paediatric cardiology. Without wishing to play down the problems at Ashworth, it seems obvious that Bristol, involving the needless deaths of many children, was in a different league. At a time when psychiatry is working hard to reduce the stigmatisation attached to patients, a comment of this nature appears gratuitous and destructive. The events which prompted Fallon report were serious, but must be kept in perspective. It can be argued that the problems were less serious than the patient abuses which led to the first Ashworth report. A true disaster in high security is when an escape leads to death or injury, as has happened over the last few years at Brixton. Whitemoor and Parkhurst prisons. Each incident led to a highly critical inquiry, but none recommended closure of the institution concerned. Why should psychiatry adopt a harsher standard?

Many aspects of the Fallon report will be quickly forgotten. The health secretary buried the headline recommendation within 24 hours. The ill-feeling created within the profession will linger much longer, and it is here that the true lessons should be drawn, about psychiatrists involvement in inquiries. I have seen many examples of retired psychiatrists sitting on homicide inquiries. I know of one example of a junior consultant sitting on such a panel, when he would not yet be eligible to be an examiner. I know of one medical member who refused to sign up to conclusions which he could not endorse. eliciting from the secretary the response that they "prefer retired psychiatrists who are more ready to criticise colleagues". We cannot control the inquiry process, but we can influence psychiatrists' participation in it. The College should draw up guidelines, covering both selection and the doctor's role. The process is too important to be left to chance, and should be as subject to clinical governance as anything else that we do.

\section{References}

BLUGLASS, R. (1992) The spectal hospitals should be closed. Britsh Medical Joumal, 306. 323-324.

FALLON, P., Bluglass, R. EDWARDS, B., et al (1999) The Report of the Committee of Inquiry into the Personality Disorder Unit, Ashworth Special Hospital. Cm 4194-II. London: The Stationery Office.

GuNN, J. (1999) Ashworth revisited. Brittish Medical Journal, 318, 271.

The Ashworth Inquriy report can be viewed at http:/www.doh.gov.uk/fallon.htm

Antony Maden, Consultant Forensic Psychiatrist, Denis Hill Unit, Bethlem Royal Hospital, Monks Orchard Road, Beckenham, Kent BR3 3BX

\section{Improving the Care of Elderly People with Mental Health Problems: Clinical Audit Project Examples Kirsty MacLean Steel and Claire Palmer}

This book contains 43 clinical audit projects, all of which have been

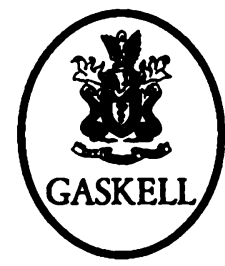
divided into topic areas and formatted into structured abstracts for ease of use. The topic areas are Referrals, Assessment, Care Plans, Medication, Clinical Care, Depression, Deliberate Self Harm, Suicide, Organisational and Managment Processes and Discharge.

\section{Features}

'Live' examples of clinical audit projects

Advice from the people who carried out the clinical audits

Readership

Old Age Psychiatrists, Psychologists, Audit Co-ordinators, Nurses

\section{August 1999, f15.00, Paperback, ISBN 1901242382}

Royal College of Psychiatrists, Book Sales, 17 Belgrave Square, London, SW1X 8PG Tel: 01712352351 ext 146, Fax: $01712451231,9.30 \mathrm{am}-2.00 \mathrm{pm}$ 